DOI: 10.21892/978-958-5547-66-7.3

\title{
3. Understanding the pharmaceutical patent system: an essay about the need to take its protection-access tradeoff seriously
}

Iván Vargas-Chaves ${ }^{1}$

As a result of the doctoral research developed by the main author (Vargas-Chaves, 2017), it was identified the evolution and perspectives of the pharmaceutical patent in the international trade system, as well as it future legal research needs in this topic, both immediate and long-term. Furthermore, a number of problems of public health were highlighted in which the patent-term-extension mechanisms have produced a lack of access to medicines.

These reflections are presented in this report, in order to propose a discussion from the issue of justified exceptions to patent rights, since such general interest ultimately responded to public health, which is of paramount importance. As reported in the doctoral thesis, the patent regime for pharmaceutical inventions often finds this priority a source of seemingly irreconcilable tensions between the right of access to medicines and the fostering of pharmaceutical innovation through the exclusivity provided by the patent.

As far as policy is concerned, this reality poses a significant challenge to the Spanish State by regulating the pharmaceutical sector so that it might fit into the newly emerging scenario. Thus, the Higher Governing Board of Pharmacy was created as a body for decision-making on scientific and administrative issues related to drugs. An example of this is the pharmacy ordinances issued by Royal Decree of 18 April 1860, granting pharmacists drug production exclusivity throughout the Spanish territory.

1 Dott. Ric. (Ph.D.), University of Palermo, Italy; Doctor of Juridical Science, University of Barcelona, Spain. Docente investigador de la Corporación Unversitaria del Caribe - CECAR.

2 Ph.D. in Bioethics, Universidad Militar Nueva Granada, Colombia. 
However, returning to the mentioned tensions, on the issue of (i.) innovation support through exclusivity, the Law of 30 July 1878 first adopted the acceptation of patent to replace the so-called privileges; and in terms of (ii.) guarded general interest concerning public health, it was with the Industrial Property Statute, Royal Decree-Law of 26 July 1929 until it became Republic Law of 16 September 1931, that the compulsory license for the exploitation of a patent in favor of a third party was conceived as a mechanism to facilitate access to inventions when their owners lacked technical or economic capacities to develop the patented product or process on their own.

As may be inferred, both regulatory initiatives are strongly focused on the need to promote the development of new drugs and facilitate access to them, at least in specific situations, establishing a precedent in the general interest and social role of inventions.

Nonetheless, regarding pharmaceutical inventions, it should be noted that Article 20 of the Law of 16 May 1902 and the Paris Convention of 1883 had by then excluded the protection granted by patents to medicines of all kinds, understood as pharmaceutical products themselves. For these purposes, as can be gathered from the text, Royal Decree of 7 December 1933 drew a dividing line between medicinal products for human use and those for veterinary use.

The importance of this regulation lies in the fact that the Order of 14 May 1934 left the door open for the Spanish pharmaceutical industry to establish its own regulations regarding the production and distribution of drugs, vaccines, serums, and disinfectants. Indeed, the foregoing set the bases for the strengthening of policy-making in the pharmaceutical industry, alongside the consolidation of the industrial aspect itself, since, as yielded by research estimates, there were nearly a thousand drug manufacturing laboratories with export capacity at the time.

And even though the patent on pharmaceutical products had not yet been conceived under Spanish law, our findings and the events addressed here lead us to believe that the need to protect this type of innovations was a fact.

Accordingly, (i.) in the late forties, by establishing guidelines and rules for the management of the research results obtained by institutes 
and under their sponsorship, public bodies such as the Spanish National Research Council (CSIC) expressed the major role-played by patents in terms of protecting industry and national interest, where health is indeed a crucial concern;

(ii.) the activity of the pharmaceutical industry begins to be taken seriously, since by implementing new requirements for this industry in the fifties and sixties and demanding that, alongside safety parameters, laboratories comply with efficacy standards proven through controlled clinical trials for the approval of new drugs, medicinal substances and proprietary medicines. This opens the door to the protection of the data obtained from such trials in the form of a sui generis patent-related right;

(iii.) from a theoretical perspective, a new era begins where new technologies become a strategic axis in the increase of aspects such as a country's gross domestic product, as was proposed in The Solow Residual, from which the need to urge governors to foster policies for the protection of new creations was inferred, and, according to the conclusions drawn from Robert Solow's theory by certain experts in the area, especially in the field of pharmaceuticals.

In fact, moving beyond theory, our findings show that, in practice, the pharmaceutical industry had a powerful start followed by a rapid rise, on the one hand thanks to investment in it, which allowed laboratories to conduct numerous clinical trials that led to the production of once unimaginable medicines such as antibiotics, diuretics and antidiabetic drugs, among many others and, on the other hand, because, with the rise of molecular biology and biotechnology, the sector intensified research for the production of new drugs, becoming a referent among the rest of innovative sectors in intensive technological $R \& D$. In short, patent protection of these inventions was already a pressing need, thereafter becoming the great challenge to be faced by the Spanish legal system.

However, this was not the only challenge to be faced by Spanish law in this area, since the issues addressed to adjust the forthcoming patent system to the demands of a society immersed in a process of globalization and regional integration were also diverse and complex. Law 11/1986 on patents ended a process that had involved intensive discussions and failures. 
Not for nothing were initiatives such as the legislative draft presented on 3 April 1982 before the Spanish Parliament rejected.

Patent law was finally introduced in Spain as part of a standardized patent regime by which states approved procedures to enable a future flow of inventions among them within an effective protection framework. Furthermore, such 'future flow' was actually the main goal of regulatory initiatives such as the Patent Cooperation Treaty or the 1973 Munich Convention and, certainly, the desired objective of the new European Community scenario that advocated effective free movement of goods as a premise for the achievement of true economic union in Europe.

Likewise, this background proved very positive for the pharmaceutical sector, as revealed by the doctoral research analysis of the measures that were becoming implemented to safeguard the interests of a growing economic and industrial engine, part of which was a powerful industry that was benefited by the commitment of the member States to include pharmaceutical products as patent-eligible inventions.

Spain was no exception and, as observed, during the transition period that preceded its entry into the European Economic Community, the commitment to integrate the protection of chemical and pharmaceutical inventions in its regulatory framework was undertaken more than a matter of political and social economy than as a technical and legal issue. The reason, as mentioned, is that until then, Spain's pharmaceutical industry had been clearly subject to other markets, depending upon them to obtain supplies of substances required to produce its drugs.

It is also unquestionable that this background provides a whole new setting for the research objective since, besides the above, the measures that were taken to reconcile Spain's patent system included both substantial changes in compulsory licenses, and procedural changes, envisaging for the first time the reversal of the burden of the suspected infringed in patent infringement lawsuits.

Another conclusion drawn from the historical analysis conducted is that the above gave rise to a major challenge for the Spanish State, which was faced with the need to adjust a new and significantly complex element such as a new patent law to a system designed to fit into the, at the time, 
new landscape of private international law and European Community patent law.

Proof of this are the consequences that revolved around Spain's accession to the 1973 Munich Convention, one of them being the problem posed by the periods established to invoke the reservations referred to in article 167 of such instrument, and only for chemical and pharmaceutical products.

Regarding the recognition of pharmaceutical products as patentable inventions, the 1973 Munich Convention was the instrument that paved the way to this new reality where the economic exploitation of these inventions in member states was accepted as attached to their owners, although this was already an acknowledged fact in countries such as Ireland and Germany.

However, whereas, beyond the opening it involved, this Convention was not the instrument that achieved the goal -which was accomplished by the TRIPS Agreement, which will be addressed below-, it was the next logical step to adjust Spanish law to fit into the new international scenario and the solution to the problem posed by the Spanish pharmaceutical industry's dependence on other markets.

We have so far highlighted the main conclusions as far as the evolutionary process of pharmaceutical patent protection is concerned. We will hereafter look closer into the reflections drawn from the time when pharmaceutical patent protection entered into force in the Spanish legal system onwards. This covers the time after the stage of transition, which lasted until 7 October 1992, even though Spain's reservation was expected to operate for only one year, that is, until 7 October 1987.

Nonetheless, and as observed, the decision to exert the right to reserve was not only made by Spain, but also by other states that could be cataloged among the "least technologically advanced". Turkey and Portugal, for example, took the decision to express their disapproval of the rigid monopoly that the coming European patent system would entail.

Accordingly, in Spain, where the protection plan used for pharmaceutical products had been thus far based on process patents, certain common practices such as the vindication of the so-called analogous procedures, or the purchase of intermediate products by Spanish 
laboratories, could be detected on the international markets where the exclusivity provided by patents was nonexistent.

This brings us back to the circumstances that led to the above mentioned 'pressing need' to protect pharmaceutical product inventions in Spain through a system that, despite criticism for its rigidity, was, we insist, essential to ensure effective protection of the interests of innovative pharmaceutical laboratories, both in those countries that were reluctant to contemplate this channel, and in the rest of countries, non-European in this case, that signed the TRIPS Agreement, which is the international document that finally consolidated pharmaceutical patents as a requirement to become part of a new scenario in WTO driven international commerce.

Against this background, by the adjustment of pharmaceutical patent protection to the Spanish legal system through the TRIPS Agreement (WTO, 1994), Spanish patent law manages to finally align with that of developed countries at the time. And this was possible because the legal solution that enabled it, envisaged the modification within the Agreement of the section listing the circumstances that prevented the patentability of pharmaceutical products, as reflected in Law 11/1980 on patents, and despite the fact that the Munich Convention, to which Spain was already a party, also envisaged this channel, although with a later implementation date due to the right to reservation.

Another highlight is the Agreement's role as a global milestone in the field of intellectual protection and its development in its various spheres of action, on the one hand, and as an instrument with considerable impact on the internal legislation of the acceding states, on the other hand.

The declared aim of all this was to widen the scope and improve the international trade scene, overcoming many of the barriers that prevented its progress, such as a patent system that was not globally standardized and required common bases to foster $\mathrm{R} \& \mathrm{D}$ and assert owners' rights against a series of practices that infringed them, such as the activities of the noninnovative pharmaceutical industry.

Within this framework, it seems clear that by laying the foundations to govern pharmaceutical patents in terms of international trade and internal regulations, the Agreement provided for a broader protection of innovative laboratories' rights that, in the case of European patents claiming chemical 
and pharmaceutical products -naming Spain- were applied for before 7 October 1992, or with equal claims with priority deadlines before such date, or pending granting according to the date of implementation of the Agreement in this country, becoming validated under article 70.7 of the Agreement.

In fact, the implementation of pharmaceutical patent protection through the TRIPS agreement posed a real challenge for Spain's legal system because of its retroactive effect on a scenario already built from formerly consolidated conditions. In particular, these include the legal and practical effects of the application of articles 27,70.2 and 70.7 of the Agreement on rights established under the previous regulation. It all finally comes down to the tension caused by preventing new laboratories to enter the market as competitors supported by the implementation of the mentioned rules, versus infringement upon the interests of laboratories that were already operating on the market.

Nevertheless, beyond this tension and the evolution of the jurisprudential precedent that deserved full attention as part of the historical review of pharmaceutical patents in Spain, emphasis should be placed on the trade openness that, as underlined, was introduced in the case of pharmaceutical products through the TRIPS Agreement (WTO, 1994).

As well as being one of the many globalization processes driven by the WTO, this openness was a framework of reference for the formulation of pharmaceutical R\&D policies based on multilateral trade regulations. It is not surprising that the analysis of the jurisprudential precedent and casuistry leads to the conclusion that a state's market size and the nature of its R\&D capacities largely determine the potential effect of intellectual property rights on policies aimed at fostering strategic areas of innovation and development.

Along these lines, governments themselves, mainly in the countries mentioned in chapter five as belonging to the 'economic north', are more inclined to strengthen their intellectual property regimes when their industries' intangible assets contribute substantially to maximizing national wealth. However, it is also clear that each sector's structural characteristics and the nature of their respective scopes of activity are decisive in the shaping of the policies to be made, since the needs and expectations of an 
industry such as the pharmaceutical are not always the same as those of others devoted to the production of intangible assets, such as the cultural content industry, to mention but one example.

While at this stage we maintain that the TRIPS Agreement (WTO, 1994) has been a fundamental axis for the pharmaceutical sector and, most especially, for innovative laboratories whose $R \& D$ processes are supported by the exclusive rights granted by patents both at the domestic level and at that of international trade, we must also draw attention to the issue of the Agreement's impact on laboratories that produce generic drugs, not as a sector that necessarily intends to benefit from the former, but as suppliers of the domestic market of developing countries, since the low prices of these drugs make them accessible to the general population, safeguarding such right and thereby the right to health care.

With their entry into the international trade market, it was no surprise that developing countries had reasonable expectations about taking a leap and moving into the new medication market. Currently, decades after the promulgation of the Agreement, this is yet to become a reality in most of these countries, leaving open whether patents, at the macro level, are appropriate for fostering pharmaceutical $R \& D$ in such countries. Nevertheless, without the intention of generalizing, we believe that the impact of intellectual property rights on the processes involved in the development of new inventions is indeed always subject to a number of factors -such as the availability of raw materials or local government incentives, among others- that goes beyond mere exclusivity in production and marketing.

Nonetheless, the major problem is the hovering tension between access to drugs versus the mentioned exclusivity. This is why the WTO issued the 2001 Doha Declaration on public health and trade-related aspects of intellectual property rights. The decision is based on two axes: (i.) the preamble to the TRIPS Agreement (WTO, 1994) stating the desire to reduce distortions and impediments to international trade, promoting effective and adequate protection of the interests of the holders of intellectual property rights and (ii.) recognition of the specific needs of the least developed member states, such as improvement of patients' social and economic well-being. 
As far as we are concerned, the Declaration takes into account the concerns of the early 2000s about anticipated consequences in terms of access to medicines, several of which still persist to date. Thus, Colombia, a country where equal access to drugs, a reality in the economic north, is still a utopia, became the arena for a conflict between the government and the global healthcare company Novartis over declaring the drug product Glivec of public interest with a view of issuing a compulsory license on it, not to mention other high-profile cases in countries such as South Africa, India or Brazil.

Thus, the concerns taken into account in the Declaration revolved around the adoption of measures to safeguard public health interests, creating a very favorable panorama for hundreds of millions of patients in the world who do not have equal access to medication. Noteworthy among the measures adopted is the right of member states to use the Agreement's flexibilities, particularly in terms of parallel imports and compulsory licenses.

In our opinion, this is the very foundation of the recognition in international trade of the power of member states' governments to take such measures as may be deemed appropriate to protect public health in the event of a coalition with the interests of patent holders. An analysis of the Agreement's provisions shows that it pays close attention to (i.) economic disparities among member states, while also (ii.) providing for exemptions and limitations to rights, in accordance with the public interest, for cases such as a predictable national emergency.

Regarding the international trade system, member states have a certain degree of freedom of choice to redirect their public policies in terms of access to drugs, since neither the concept itself nor the scope of what may constitute a patentable invention is defined in the body of the TRIPS Agreement (WTO, 1994). The margins for interpreting the requirements for the granting or refusal to grant patent rights are not defined either. This gives states some discretion to adjust both their own definitions and their legal scope to social and economic considerations.

Additionally, as noted in the study, this allows states to design their regulations so that they may include different methods, such as the establishment of specific requirements of the standardization of domestic 
regulations to those of a state signatory to a TRIPS-Plus Agreement, so that only 'justified patents' are granted. However, one of the implications of this is that it could produce the opposite of the desired effect by tilting the balance between access to medication and the owner's rights in favor of the latter. This is the case with the mentioned extended terms of protection to compensate for undue delay in the patenting process.

We believe that this not only infringes the right of access to medicines but that it is also detrimental to growing innovative pharmaceutical industries at the local level. And, returning to the case of Spanish laboratories, whether it is plausible or not to develop a strong local pharmaceutical industry should be the subject of future discussion. It is important to bear in mind that a strong regulatory regime in terms of intellectual property is crucial to structure national capacities in innovative sectors such as the pharmaceutical, which is, besides, highly competitive.

Historical evidence of this can be found in the fact that leading countries in this field, such as Germany, Switzerland or the USA, have greatly benefited from having an intellectual property system conceived to strengthen such capacities. While not intending to wander off the topic, the case of Germany is especially interesting because its patent system contributed to boosting local innovative industries through reverse engineering and by absorbing emerging technologies from abroad.

Nevertheless, the mentioned balance finally tilts against patients when the adoption of ever-greening strategies and other practices for extension of the exclusivity period that, taking advantage of regulatory gaps, divert exclusivity away from its role of fostering $R \& D$ to a playing field where patented products and processes, being minor changes, do not contribute to the state of the art nor to the fulfillment of the social function of intellectual property rights.

Indeed, the real goal is to keep competitors, in this case, generic medicine laboratories, out of the market to maintain prices at levels that suit laboratories engaged in these practices, prices above those that would be set in competitive scenarios. This is where the measure of autonomy and room to manoeuver that states might have come into play to prevent the proliferation of applications for pharmaceutical patents on molecules that do not constitute a true innovation. 
This is one of the reasons why in this study we chose to emphasize the feasibility of adopting certain national measures that, tough equally compatible with the TRIPS Agreement (WTO, 1994), may correct this type of practices. Thus, the international trade system, through the WTO, provides for the authorization of its member states to design and apply their own regulations concerning patent rights on pharmaceutical inventions.

In the light of this research, and aside from the legal controversies addressed in it, the recent reality of certain generic medicine laboratories in Spain has been far from encouraging, since the trend in the area has shifted towards the innovative sector. More striking, however, is the case of some of these laboratories that, having been authorized to produce and commercialize by the Spanish Agency of Medicinal and Healthcare Products (AEMPS), were forced to stop doing so when the right existing since the 1973 Munich Convention was acknowledged by precedent in favor of innovative laboratories.

This new landscape led to the submission to the Court of several legal controversies regarding pharmaceutical product inventions that, per the claimants, should not be patent-protected, or at least this should be the case with those registered before 7 October 1992. However, beyond the legal aspects of the carefully analyzed case studies included in the previous chapter, we believe that a reflexive approach requires close attention to pharmaceutical patents in relation to access to medication rather than considering the future of pharmaceutical patents only as an incentive mechanism for R\&D per se.

This is even more significant if both case-law and the normative area guarantee the innovative pharmaceutical industry such incentive. We should bear in mind the law's commitment to strengthen the different innovative sectors, which is pursued through the creation of rights such as supplementary protection certificates or test data protection. Both are mechanisms to extend the exclusivity of pharmaceutical inventions after a patent has expired. Our concern in this regard is that they are barriers that block access to medication, especially in developing countries.

Indeed, after activating these two mechanisms by granting either of the rights, innovative laboratories would become qualified to prevent generic drug laboratories from producing the drugs whose patents expired. First 
because the effective patent term becomes extended and, second, because by claiming ownership of the test data yielded by medicine validation research they can force generic drug laboratories to produce their own data and, as mentioned, this could even lead to opposing the transfer of these data by regulatory agencies to other public entities.

Over the course of the research, these situations gave rise to several questions: what would happen if the body in charge of assessing the safety of a drug was denied access to the relevant clinical data? Would the right to health and, therefore, the right to life of patients taking drugs that have not been properly assessed be guaranteed? In a second scenario: would this same right be guaranteed in a setting where hundreds of millions of patients every day are unable to access drugs or healthcare because of the high prices of medicinal products?

When analyzing such issue in the light of the international trade system, and of the TRIPS Agreement in particular, our questions are a shared issue with Ortega-Gómez (2016), who believes that this instrument does not improve the picture since, after the entry into force of the TRIPS Agreement in a large number of developing countries, the high cost of medicinal products under patent protection has become an almost insurmountable barrier to the citizens of these countries' access to essential, new and high-quality drugs.

Since the Agreement fails to include clauses and mechanisms that should serve to mitigate the negative effects of the agreement, and this is exacerbated by the fact that we insist, the burden of drug acquisition costs is borne by patients themselves or otherwise by public healthcare systems that are on the verge of financial collapse due to these high costs.

Added to this, we must also mention the blocking of compulsory licenses with data exclusivity since, as we stated, even when approval of a generic drug has been obtained, it is beyond the question that the laboratories in charge of producing them should also hold the data recorded by the local healthcare regulatory agency. Let us also remember that compulsory licenses are the mechanism par excellence that allows drugs under patent protection either to be produced as generic products or to be imported, without the need to obtain the owner's permission for the effects of mitigating health emergency situations. 
To close this section, we acknowledge the fact that the 2001 Doha Declaration (WTO, 2001) marked a significant step towards laying the foundations for access to medicines, although statistics indicate that, since then, the mentioned reality faced by hundreds of millions of patients that die while waiting for timely and proper treatment has not particularly improved. This concern was addressed in the Sixty-Seventh World Health Assembly held in 2014, where some of the guidelines for implementing the Doha Declaration postulates were discussed, although this is not a short- or even mid-term perspective, but still a utopia.

Therefore, we believe that the responsibility to solve the situation should rest with governments, because of their power to actively intervene in the pharmaceutical market. Thus, policies on access should be redirected, without infringing patent owners' rights, towards securing due remuneration for the efforts invested in the development of new medicinal products.

This could be achieved, for example, through a coordinated strategy by University, business sector and state with a view to intensifying in-house research and the development of new drugs by building alliances between these sectors. In the end, it is about these other two sectors accepting their social responsibility and redesigning their role in society to proactively search for solutions to the problem.

\section{References}

Ortega Gómez, M. (2016). The right of Access to Medicines and the right to a patent in developing countries. Revista de Bioética y Derecho Perspectivas Bioética, 37, 23-36. Retrieved from http://scielo.isciii. es/pdf/bioetica/n37/articulol.pdf

Vargas-Chaves, I. (2017) Patentes farmacéuticas: balances desde la evolución en su regulación, realidades en el comercio internacional y perspectivas en materia de salud pública [Tesis doctoral]. Universidad de Barcelona: Barcelona.

WTO. (1994). AGREEMENT ON TRADE-RELATED ASPECTS OF INTELLECTUAL PROPERTY RIGHTS. París. Retrieved from https:// www.wto.org/english/docs_e/legal_e/27-trips.pdf 
Understanding the pharmaceutical patent system: an essay about the need to take its protection-access tradeoff seriously

WTO. (2001). DECLARATION ON THE TRIPS AGREEMENT AND PUBLIC HEALTH. En Ministerial Conference. Doha: World Health Organization. Retrieved from https://www.who.int/medicines/areas/ policy/tripshealth.pdf?ua=1 